\title{
Article \\ Numerical Simulation Investigation of a Double Skin Transpired Solar Air Collector
}

\author{
Charles Berville $^{1}$, Florin Bode ${ }^{1,2} @$ and Cristiana Croitoru ${ }^{1, *}$
}

Citation: Berville, C.; Bode, F.; Croitoru, C. Numerical Simulation Investigation of a Double Skin Transpired Solar Air Collector. Appl. Sci. 2022, 12, 520. https://doi.org/ 10.3390/app12010520

Academic Editor: Yosoon Choi

Received: 23 November 2021

Accepted: 31 December 2021

Published: 5 January 2022

Publisher's Note: MDPI stays neutral with regard to jurisdictional claims in published maps and institutional affiliations.

Copyright: (C) 2022 by the authors. Licensee MDPI, Basel, Switzerland. This article is an open access article distributed under the terms and conditions of the Creative Commons Attribution (CC BY) license (https:// creativecommons.org/licenses/by/ $4.0 /)$.
1 CAMBI Research Centre, Technical University of Civil Engineering Bucharest, 021414 Bucharest, Romania; charles.berville@gmail.com (C.B.); florin.bode@termo.utcluj.ro (F.B.)

2 Mechanical Engineering Department, Technical University of Cluj-Napoca, 400114 Cluj-Napoca, Romania

* Correspondence: cristiana.croitoru@utcb.ro

\begin{abstract}
Transpired solar collectors (TSC) are one of the most popular solar thermal technologies for building façades. TSC use solar energy to heat the absorber surface, which transmits thermal energy to the ambient air. A variant of TSC, namely, a double skin transpired solar collector (DSTSC), has been analyzed in this paper, thus providing guide values and a technical point of view for engineers, architects, and constructors when designing such transpired solar collectors. Three important parameters were addressed in this study through numerical simulation: the influence of a separation plate introduced in a TSC, turning it into a DSTSC; the air layer thickness influence on the performance of the collector; and the influence of the used absorber materials for the separation plate material. Greater heat exchange efficiency was noticed for the DSTSC at every imposed airflow rate compared with the TSC. Regarding the thickness of the collector, the efficiency gradually increased when increasing the solar collector thickness until it reached a value of $20 \mathrm{~cm}$, though not varying significantly at a thickness of $30 \mathrm{~cm}$.
\end{abstract}

Keywords: transpired solar collectors; double skin transpired solar collector; solar thermal technology; solar energy; building façade; TSC; DSTSC

\section{Introduction}

A great recent challenge has been to reach world climate-neutrality by 2050, and at this moment, with the buildings sector still being responsible for $40 \%$ of greenhouse gas emissions and $36 \%$ of final global energy consumption, it is clear that perspectives must change [1]. For the construction of skyscrapers during the 20th century, architects and building designers focused on high-rise buildings made of concrete and metal structures wrapped in glass façades. These shiny and high-energy-consumption buildings are no longer in accordance with the standards and needs of our times. Thus, strict energy requirements are emerging around the world, making buildings and energy systems more efficient and sustainable. The Renovation Wave and Nearly Zero-Energy Buildings (NZEB) regulations in Europe [2] are part of the objectives of this global movement for highly efficient new buildings and highly efficient deep renovated buildings to prepare the European Union for a decarbonised and clean-energy future.

To work towards a successful energy transition, a new energy system must be proposed, and the architecture of buildings must be thought of in a more sustainable way. The energy-efficient solutions can be embedded in the building structure, and from these, our attention is focused on the building envelope/façade. Building façades can facilitate the access to a huge source of energy, which, for a long time, has been ignored in the building conception phase. The building envelope has the capacity to capture large amounts of free energy from the sun [3].

Active ventilated façades, such as Transpired Solar Collectors (TSC), have the advantage of insulating the building envelope and providing heated air for the building's 
thermal needs [4]. Thus, the TSC can reduce the building's energy use and provide a clean, renewable energy source for air heating.

In this wide domain of Building-Integrated Solar Thermal Systems, we find the Transpired Solar Collectors (TSC) as being among the most efficient ones. TSCs can be glazed (GTSC) or unglazed (UTSC), usually being implemented on large-scale façades, such as those used for industrial buildings, office or multi-family residential buildings, as well as for ventilation and space-heating during cold periods. This kind of solar air collector has the advantage of being affordable and easy to integrate for a building retrofit. Peci et al. found [5] that the use of modular UTSC could cover ventilation heating needs for an apartment for about $74.6 \%$ of the days examined during their study. Furthermore, in addition to air heating purposes, UTSCs have the potential to be used for nocturnal passive cooling, and this increases the annual yield of such a system [6].

During the last three decades, transpired solar collectors have been intensely analyzed through numerical and experimental approaches. Computational Fluid Dynamics (CFD) have initially been applied to TSCs via 2D numerical models [7] highlighting heat transfers occurring on the perforated absorber plate. The same team conducted by Gunnewiek et al. [8] revealed the importance of the suction velocity to mitigate the negative impact of the wind on thermal behaviours of TSCs. They found an optimal range of suction velocity from 0.0125 to $0.039 \mathrm{~m} / \mathrm{s}$.

In the early 2000s, Van Decker et al. [9] highlighted several specificities concerning TSC, such as the non-uniform distribution of the heat transfer through the collector. They assessed that heat transfer occurred for about $62 \%$ on the front, $28 \%$ in the hole and $10 \%$ on the back of the plate.

In 2002, a group of researchers led by Gawlik and Kutscher [10] profoundly contributed to the understanding of the thermal behaviour of TSC, focusing on the absorber plate characteristics, the suction velocity, and the wind speed [11]. One of the main advances in their work was observing the low influence of the conductivity of materials on the thermal behaviour of the TSCs, which only a few works in the literature have demonstrated. Other parameters, like the pressure drop inside the solar collectors, show a significant role in the design of such systems [12]. It has been found that wind speed and airflow rate are the most influent parameters on transpired solar collector performance [13]. Seminal contributions have been made by Croitoru et al. regarding the influence of the perforation shapes on the absorber plate [14], showing that round holes have lower heat transfer than lobed geometries by about $15 \%$. They also found that non-aligned and non-uniform shapes provide better performance.

Although there are many CFD studies providing key elements to understand TSC behaviors, the research remains limited, mainly due to the lack of computing power. TSCs are complex geometries incorporating many small surfaces, such as the holes on the absorber plate which compelled researchers to simplify their numerical models.

This paper presents numerical studies performed on a large-scale numerical model, regarding the parametric independence of a Double Skin Transpired Solar Collector (DSTSC). The idea of DSTSC is part of a project aiming to integrate thermal energy storage in TSC [15] with a thermal energy storage (TES) management system. The main idea of the prototype of building-integrated DSTSC, presented in Figure 1 is to use the PCM storage only when the solar energy absorbed by the perforated collector (metal plate) is not covering the heating needs (for example, for the periods when the solar radiation is intermittent). The by-pass system decreases the pressure drop caused by the TES and diminishes the energy consumption of the fan, and thus aims to increase the overall efficiency of the system. The TES management system is based on a system of dampers controlled by a function of the temperature range and heating needs. The performed research is dedicated to less-studied parameters in the literature, like distances between internal structures and the impact of low-conductivity materials. 


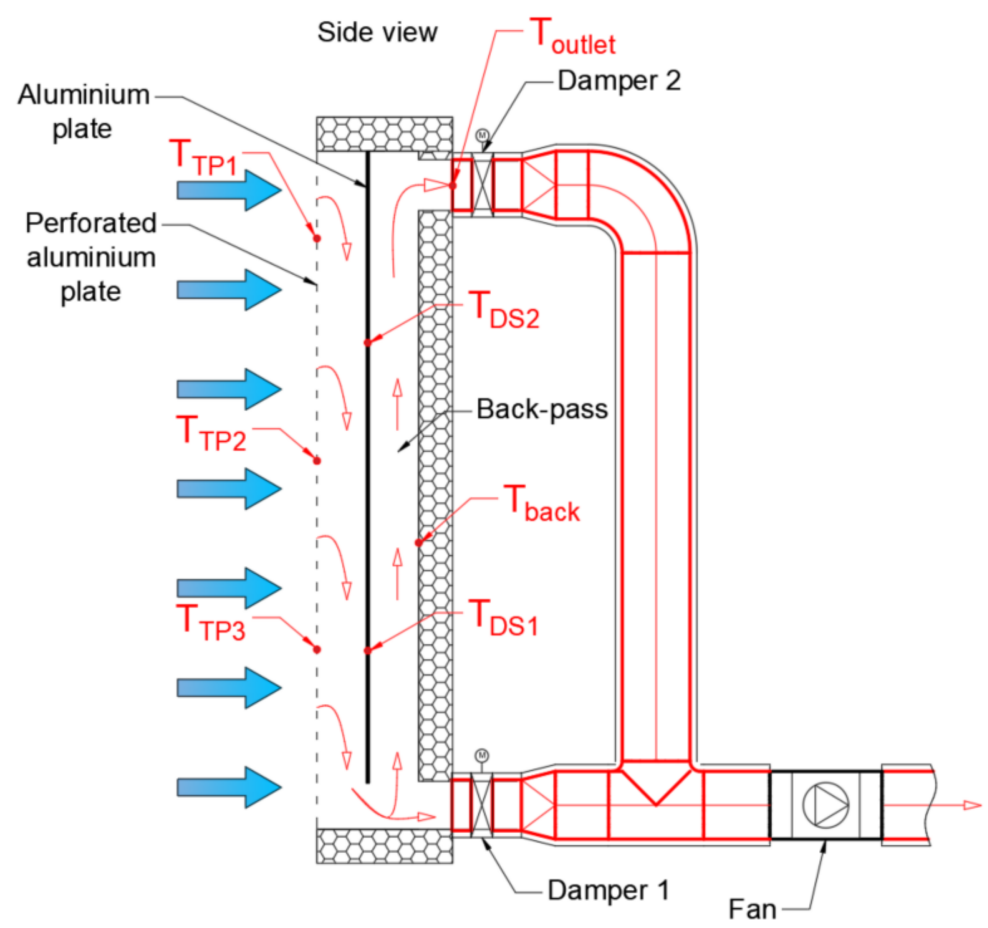

Figure 1. Building-integrated solar air collector.

The main purpose of this paper is to present the critical parameters investigated during the concept phase of a Double Skin Transpired Solar Collector prototype. The study addresses three main objectives: the determination of the influence of a second skin inside a TSC and comparison of our prototype with classic TSC to validate the potential for future uses combining with TES integrated in the back-pass; the design of a DSTSC that is easy to integrate in buildings considering lightweight materials, such as aluminum, and reduces the thickness of the collector; and finally, the study of a low-conductivity and affordable plastic-based material.

\section{Materials and Methods}

\subsection{Description of the Prototype}

Transpired Solar Collectors consist of a perforated absorber plate made of metal-based materials, a wood or metal frame with thermal insulation, and a fan. The perforations are typically distributed over the entire absorber plate; however, due to the suction of the fan, a short-circuit can appear for the holes located on the upper part of the perforated plate, as reported by Wang et al. [16]. Another issue is related to the intermittence of the solar radiation impacting the solar collector energy production. Therefore, we investigated a novel type of TSC with a double skin to mitigate these issues. The Double Skin Transpired Solar Collector investigated in this paper is presented in Figures 1 and 2. The second skin based on an aluminum black-coated plate serves three purposes. It is used to create a space for thermal energy storage behind the separation plate, in the back-pass; then, to prevent a short-circuit of the holes in the upper part of the collector; and finally, to collect the residual solar radiation passing through the holes of the perforated absorber plate, and then release this energy to the air flowing through the collector. 

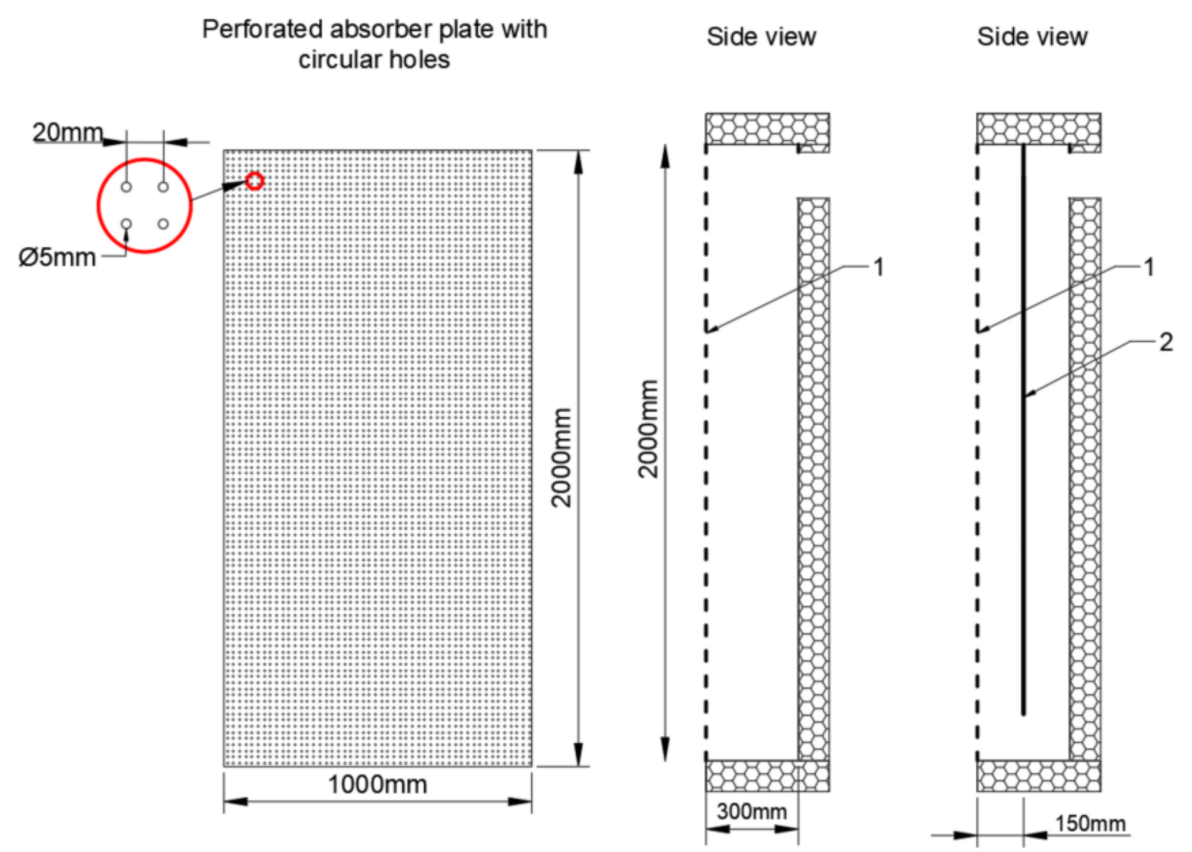

Figure 2. Scheme of the TSC (left) and DSTSC (right). 1. Perforated absorber plate made of aluminium with black coating. 2. Separation plate made of aluminium.

\subsection{Mathematical Models/Theoretical Analysis}

A theoretical approach based on energy balance equations has been used to analyze the numerical results and to obtain the thermal performance of DSTSC.

Solar air collectors are typically analyzed via two coefficients of performance [17], the heat exchange effectiveness $\varepsilon_{H X}$ and the solar collector efficiency $\eta$.

The heat exchange effectiveness is defined as:

$$
\varepsilon_{H X}=\frac{T_{\text {outlet }}-T_{\text {ambient }}}{T_{\text {absorber plate }}-T_{\text {ambient }}}
$$

where: $T_{\text {outlet }}$ is the outlet air temperature $\left[{ }^{\circ} \mathrm{C}\right] ; T_{\text {ambient }}$ is the ambient air temperature $\left[{ }^{\circ} \mathrm{C}\right]$; and $T_{\text {absorber plate }}$ is the temperature of absorber plate $\left[{ }^{\circ} \mathrm{C}\right]$.

The solar efficiency collector can be calculated with the following expression:

$$
\eta=\frac{c_{p, \text { air }} m_{\text {air }}\left(T_{\text {outlet }}-T_{\text {ambient }}\right)}{I_{T} A_{S}}
$$

where: $T_{\text {outlet }}$ is the outlet air temperature $\left[{ }^{\circ} \mathrm{C}\right] ; T_{\text {ambient }}$ is the ambient air temperature $\left[{ }^{\circ} \mathrm{C}\right]$; $c_{p, a i r}$ is the specific heat capacity of air $[\mathrm{J} / \mathrm{kg} \cdot \mathrm{K}]$; absorber plate area $\left[\mathrm{m}^{2}\right]$.

In this paper, we also analyzed the performance of the solar collector via the heat transfer coefficient. The heat transfer coefficient $(h)$ can be assessed with the following expression:

$$
h=\frac{q}{\Delta T}
$$

where: $q$ is the heat flux $\left[\mathrm{W} / \mathrm{m}^{2}\right]$ and $\Delta T$ is the difference in temperature between the solid surface and surrounding fluid area $[\mathrm{K}]$.

\subsection{Numerical Model}

A numerical model was realized in the commercial CFD software ANSYS. The governing equations were solved via ANSYS Fluent 19.0 based on the numerical finite volume method. 


\subsubsection{Geometry}

The 3D geometry was created in SOLIDWORKS software based on the real scale prototype located in the "Advanced Research Centre for Ambiental Quality and Building Physics" (CAMBI) inside the Technical University of Civil Engineering of Bucharest and presented in Figure 3. For the numerical study, only a longitudinal slice of the entire DSTSC was numerically modeled, principally due to computational resources. The real-scale prototype presented in Figures 2 and 4 had 5000 circular holes of $5 \mathrm{~mm}$ diameter, and such an expansive geometry requires a very large numerical grid composed of too many elements. Thus, we decided to model an entire slice of the collector consisting of a column of 100 holes allowing us to estimate the behavior of the whole collector.

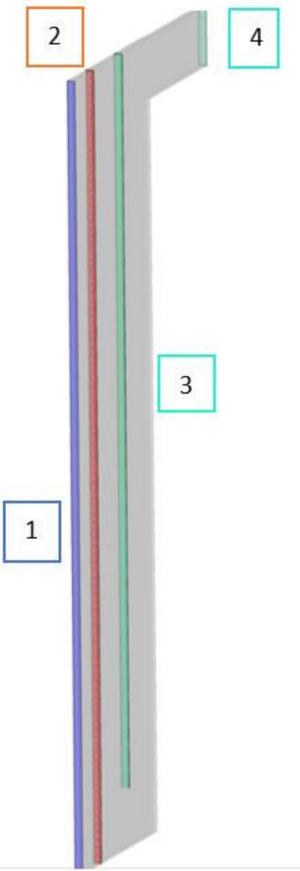

Figure 3. 3D geometry. Dimensions: $2000 \mathrm{~mm} \times 20 \mathrm{~mm} \times 300 \mathrm{~mm}$. 1. Inlet. 2. Perforated absorber plate. 3. Second plate. 4. Outlet.

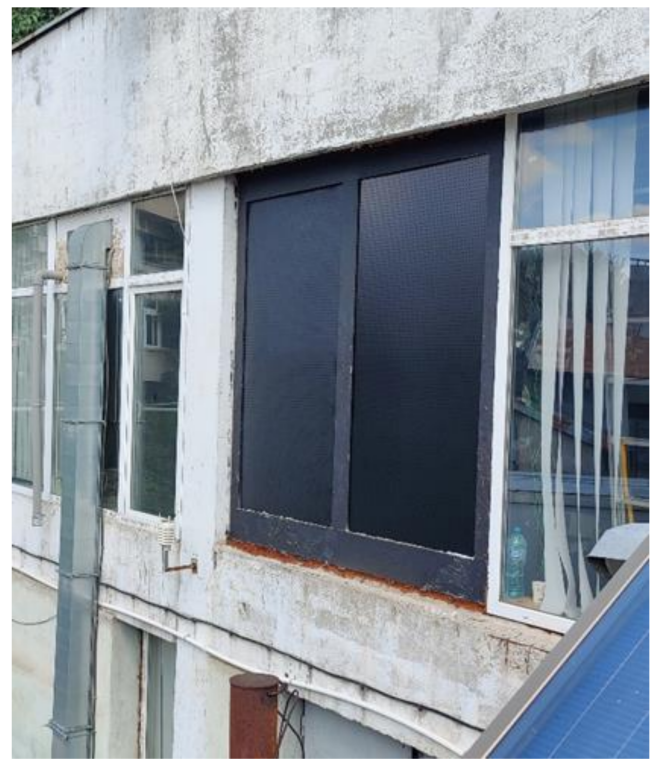

Figure 4. Building integrated Transpired Solar Air Collectors. TSC on the left and DSTSC on the right. 


\subsubsection{Model Configuration}

A high-quality numerical grid was realized with ANSYS MESH. The mesh of the DSTSC is composed of 18 million tetrahedral elements and was the result of a mesh independency study carried out in the Ref. [18]. The mesh independency revealed to us the importance of the mesh quality to correctly predict parameters such as the temperature and velocity gradients.

According to the literature, the RNG $\mathrm{k}-\varepsilon$ turbulence model is the most appropriate and reasonable when considering accuracy and computing time for numerical simulations regarding Transpired Solar Collectors $[13,19,20]$. Thus, we set the RNG k- $\varepsilon$ turbulence model combined with the Enhanced Wall Treatment option including thermal effects and pressure gradients.

The solar radiation was integrated through the surface-to-surface model after showing good convergence and accuracy in previous studies [21]. The surface-to-surface model can be computationally expensive for geometries with numerous surfaces, and was so for our case, considering that the studied geometry contained 100 holes. Thus, we created surface clusters to reduce the computation time.

The inlet and outlet surfaces presented in Figure 3 were set as the pressure inlet and mass-flow outlet. Considering that the geometry represents a slice of the real-scale DSTSC, lateral walls were set with symmetry boundary conditions to reduce the size of our computational model.

\subsubsection{Model Validation}

An experimental measurements campaign was conducted to validate the numerical simulation results. A 10-day experiment was performed during summertime from 5 to 10 August 2021 at the Faculty of Building Services in the city of Bucharest, Romania.

For this, a TSC and a DSTSC were integrated on the façade of the laboratory building (Figure 4), and one DSTSC was integrated in a container. The two collectors integrated in the laboratory façades were used to characterize the thermal behavior of both collectors in outdoor conditions.

Fans were alimented with two high-precision laboratory power supply units, ZHAOXIN. The output voltage and current were adjustable. Measuring devices and their specifications are presented in the Table 1.

Table 1. Devices' technical specifications.

\begin{tabular}{cccc}
\hline Device & Range & Resolution & Accuracy \\
\hline Flow meter & 10 to $850 \mathrm{~m}^{3} / \mathrm{h}$ & $1 \mathrm{~m}^{3} / \mathrm{h}$ & $\pm 3 \%$ of the reading \\
Pyranometer & 0 to $1500 \mathrm{~W} / \mathrm{m}^{2}$ & $0.1 \mathrm{~W} / \mathrm{m}^{2}$ & $<3 \%$ \\
Wind Velocity Sensor & 0.5 to $50 \mathrm{~m} / \mathrm{s}$ & $0.1 \mathrm{~m} / \mathrm{s}$ & $\pm 0.5 \mathrm{~m} / \mathrm{s} \pm 3 \%$ \\
Wind Direction Sensor & $0^{\circ}$ to $360^{\circ}$ & $11.25^{\circ}$ & $\pm 5^{\circ}$ \\
\hline
\end{tabular}

The validation of the CFD methodology proposed for all the cases regarding the TSC and DSTSC was done with a comparison between the CFD results and the experimental results presented in this section. The CFD investigation was carried out for a $3 \mathrm{D}$ geometry of a DSTSC identical to the DSTSC integrated in the façade of the laboratory and for the same parameters as used in the experimental study. Table 2. shows the parameters of the studied case for validation.

For the numerical simulation case, the wind speed was not integrated; thus, we chose a moment of the day with a wind velocity near zero $\mathrm{m} / \mathrm{s}$.

Comparisons were performed between numerical results and measured temperatures of the perforated absorber plate in three different points, $T_{1}, T_{2}$, and $T_{3}$, as well as for the separation plate in two points, $T_{\mathrm{DSb}}$ and $T_{\mathrm{DS} u p}$, and in one point situated on the rear wall of the DSTSC, $T_{\text {back, }}$, and finally at the temperatures of the outlet air, $T_{\text {out }}$. 
Table 2. Details of the case used for validation.

\begin{tabular}{cc}
\hline Parameters & Values \\
\hline Air flow & $450 \mathrm{~m}^{3} / \mathrm{h}$ \\
Ambient temperature & $27.8^{\circ} \mathrm{C}$ \\
Solar radiation & $454.5 \mathrm{~W} / \mathrm{m}^{2}$ \\
Direct & $354.5 \mathrm{~W} / \mathrm{m}^{2}$ \\
Diffuse & $100 \mathrm{~W} / \mathrm{m}^{2}$ \\
Wind speed & $0.3 \mathrm{~m} / \mathrm{s}$ \\
Wind direction & $220^{\circ}$ \\
Absorptivity perforated absorber plate & $0.96-0.98$ \\
\hline
\end{tabular}

Table 3 shows the comparison between CFD and experimental data. All the temperatures were predicted with an accuracy level within $6.11 \%$. Considering that experimental measurements carry a degree of uncertainty due to the intrinsic resolution and accuracy of each measuring device presented before, we considered that the proposed CFD methodology can be used for actual and further CFD simulations within reasonable accuracy.

Table 3. Comparison between CFD and experimental data.

\begin{tabular}{cccccccc}
\hline & $\boldsymbol{T}_{\text {outlet }}$ & $\boldsymbol{T}_{\mathbf{P 1}}$ & $\boldsymbol{T}_{\mathbf{P 2}}$ & $\boldsymbol{T}_{\mathbf{P 3}}$ & $\boldsymbol{T}_{\mathbf{D S 1}}$ & $\boldsymbol{T}_{\text {DS2 }}$ & $\boldsymbol{T}_{\text {back }}$ \\
\cline { 2 - 7 } & ${ }^{\circ} \mathbf{C}$ & ${ }^{\circ} \mathbf{C}$ & ${ }^{\circ} \mathbf{C}$ & ${ }^{\circ} \mathbf{C}$ & ${ }^{\circ} \mathbf{C}$ & ${ }^{\circ} \mathbf{C}$ & ${ }^{\circ} \mathbf{C}$ \\
\hline Exp & 34.1 & 39 & 39.9 & 39.6 & 36.6 & 35.9 & 34.2 \\
Num & 33.12 & 37.89 & 37.59 & 37.18 & 35.26 & 36.2 & 33.89 \\
Temperature difference & 0.98 & 1.11 & 2.31 & 2.42 & 1.34 & 0.3 & 0.31 \\
Error & $2.87 \%$ & $2.85 \%$ & $5.79 \%$ & $6.11 \%$ & $3.66 \%$ & $0.84 \%$ & $0.91 \%$ \\
\hline
\end{tabular}

\section{Numerical Results and Discussions}

\subsection{Comparison between TSC and DSTSC}

The aim of this part it is to analyze the influence of a back-pass inside a Transpired Solar Collector. Thus, we compare a usual Transpired Solar Collector with our prototype of a Double Skin Transpired Solar Collector in Figure 2.

A comprehensive numerical study was conducted, based on the two geometries previously presented in Figure 2. For each geometry we analyzed the airflow characteristics and thermal behaviour for 5 airflow rate, $100 \mathrm{~m}^{3} / \mathrm{h}, 200 \mathrm{~m}^{3} / \mathrm{h}, 300 \mathrm{~m}^{3} / \mathrm{h}, 400 \mathrm{~m}^{3} / \mathrm{h}$ and $500 \mathrm{~m}^{3} / \mathrm{h}$. The solar radiation was set as $800 \mathrm{~W} / \mathrm{m}^{2}$, with $650 \mathrm{~W} / \mathrm{m}^{2}$ of direct solar radiation and $150 \mathrm{~W} / \mathrm{m}^{2}$ of diffuse solar radiation. This section summarises the findings and contributions made.

The first difference between the two solar collectors that we observed was regarding the heat exchanger efficiency. In Figure 5 we can notice a higher heat exchanger efficiency for the DSTSC at every airflow rate. Figure 6 comes with additional information to better understand the causes of these differences regarding the heat exchanger efficiency, indeed, we observe that the efficiency of the perforated absorber plate of the TSC is much higher than for the DSTSC. The heat exchanger efficiency is based on the temperature difference between the exchanger (in this case, the absorber plate), the ambient air, and the outlet air (Equation (1)), where the higher the exchanger temperature, the lower the exchanger efficiency. This is the reason why the heat exchanger efficiency of the TSC is lower than for the DSTSC. The heat exchanger efficiency of the TSC varies from $40 \%$ to $64 \%$ for airflow going $100 \mathrm{~m}^{3} / \mathrm{h}$ to $500 \mathrm{~m}^{3} / \mathrm{h}$, while for the DSTSC, the heat exchanger efficiency varies from $45 \%$ to $78 \%$. This corresponds to a difference of the benefit of the DSTSC from $5 \%$ to $14 \%$. 


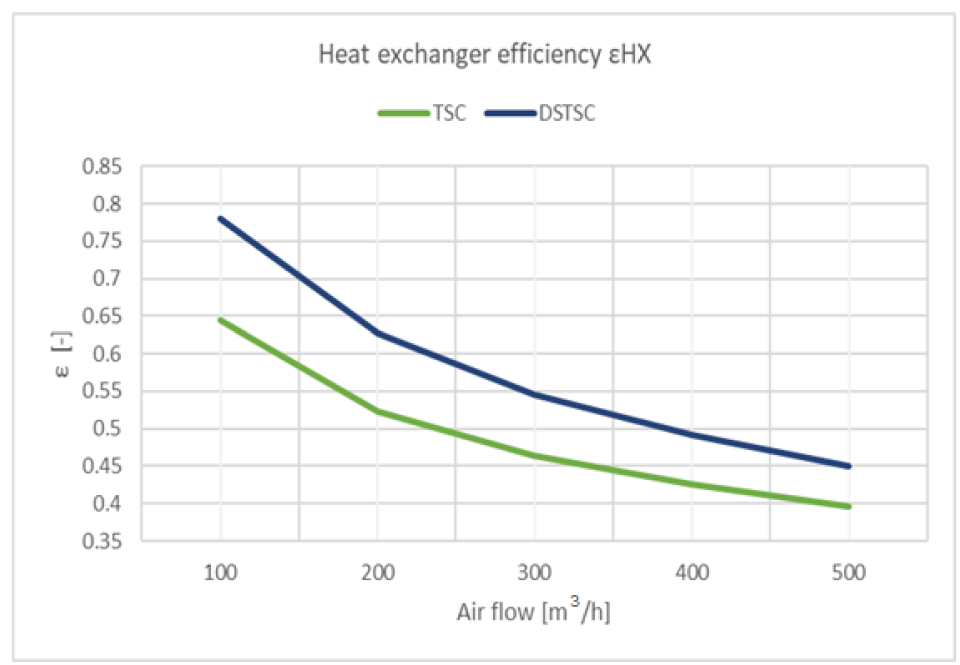

Figure 5. Heat exchanger efficiency $\varepsilon_{H X}$.

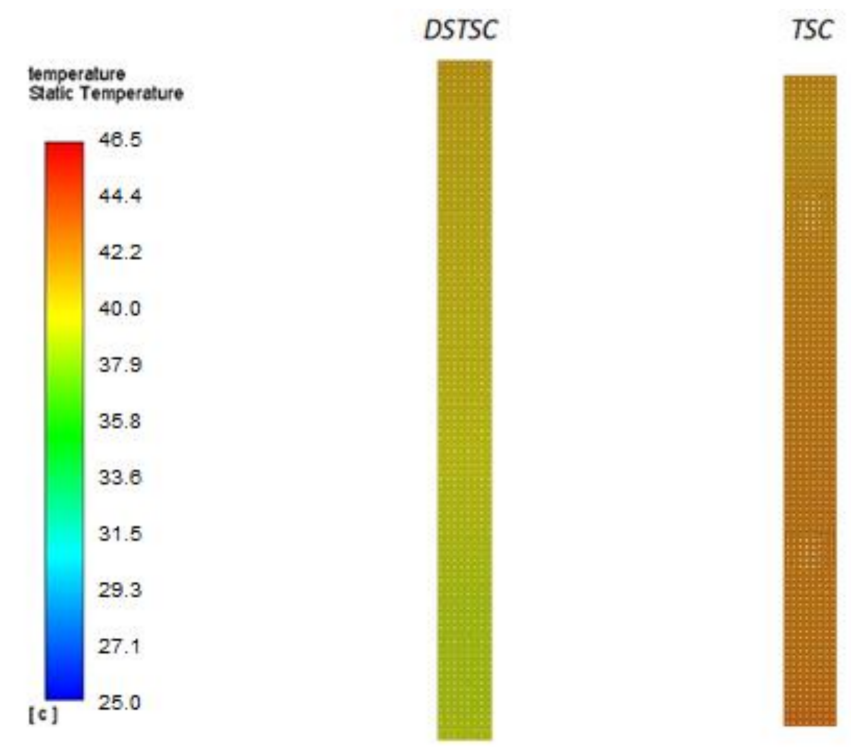

Figure 6. Temperature distribution on the perforated absorber plate for the DSTSC (left) and TSC (right) at an airflow rate of $500 \mathrm{~m}^{3} / \mathrm{h}$.

In Figure 7 it can be noticed that for airflow higher than $400 \mathrm{~m}^{3} / \mathrm{h}$, the TSC becomes more efficient than the DSTSC from the viewpoint of the solar collector efficiency. At this stage of understanding, we explain this evolution by the fact that for higher airflow, an air by-pass appears in the upper part the DSTSC. Nevertheless, the DSTSC still gives the best performance regarding the solar collector efficiency between $100 \mathrm{~m}^{3} / \mathrm{h}$ and $400 \mathrm{~m}^{3} / \mathrm{h}$. The solar collector efficiency of the TSC varies from $60.9 \%$ to $86.9 \%$ for airflow going from $100 \mathrm{~m}^{3} / \mathrm{h}$ to $500 \mathrm{~m}^{3} / \mathrm{h}$, while for the DSTSC, the solar collector efficiency varies from $66.5 \%$ to $85.7 \%$.

Figures 8 and 9 show the temperature and velocity distribution for the TSC and DSTSC at an air flow of $100 \mathrm{~m}^{3} / \mathrm{h}$. The TSC overheats a bit in the bottom part in the wooden back plate, while the DSTSC overheats in the upper part of the aluminum separation plate. The DSTSC did not overheat on the bottom because the air velocity is sufficiently high enough to extract the heat from the wooden back plate, as we can notice in Figure 10. 


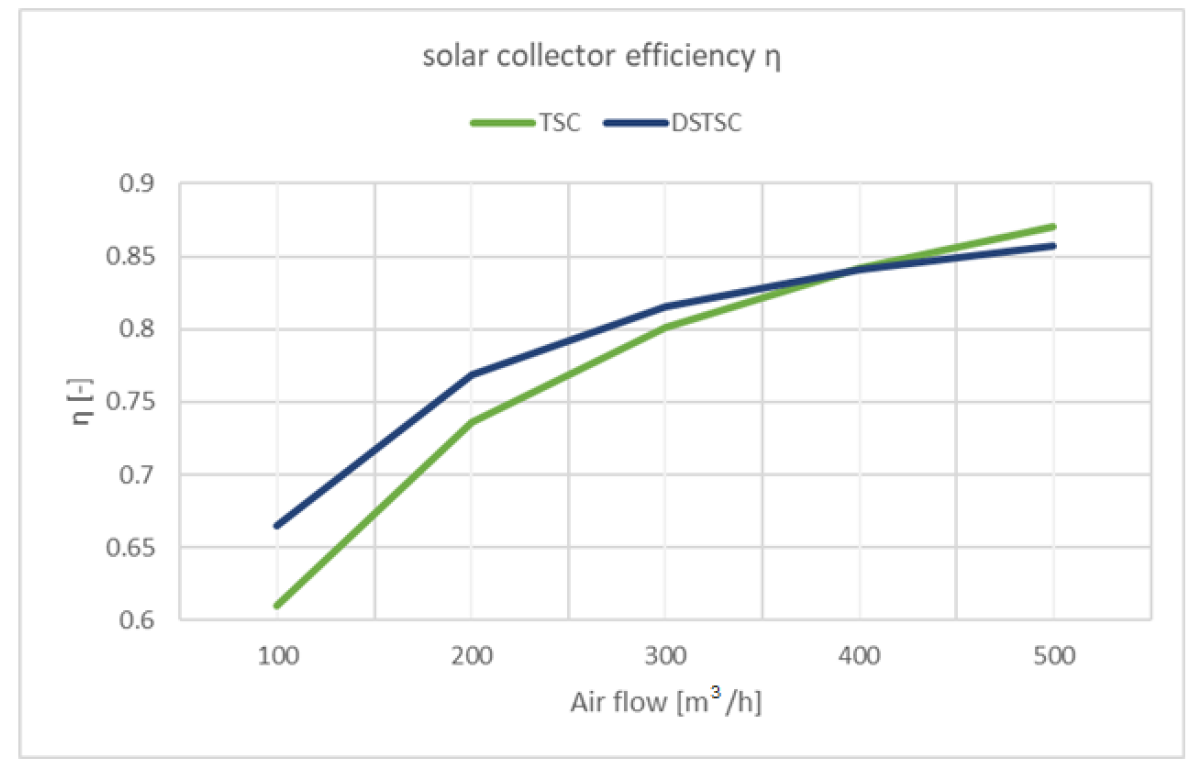

Figure 7. Solar Collector efficiency.

DSTSC

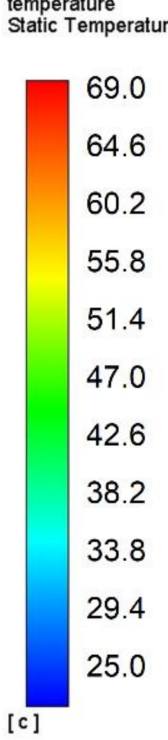

TSC

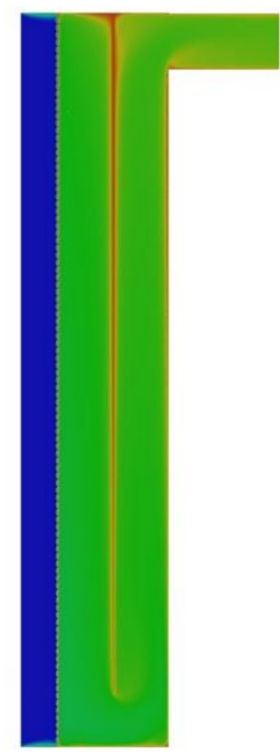

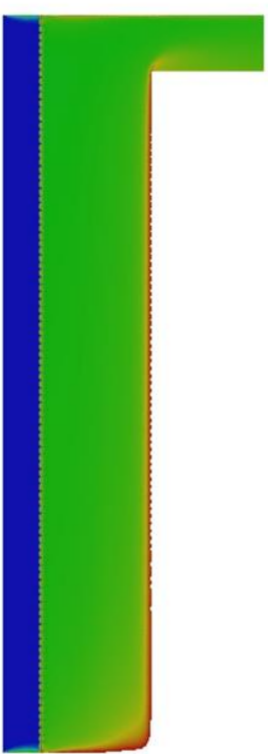

Figure 8. Temperature distribution in a median plane for the DSTSC (left) and TSC (right) at $100 \mathrm{~m}^{3} / \mathrm{h}$.

Figures 10 and 11 present the numerical results for an airflow of $500 \mathrm{~m}^{3} / \mathrm{h}$. Compared to the $100 \mathrm{~m}^{3} / \mathrm{h}$ case, the solar collectors no longer overheat, since the air velocity is sufficiently high to extract the heat from both collectors. However, we can still notice slight overheating at the bottom of the TSC. 
DSTSC

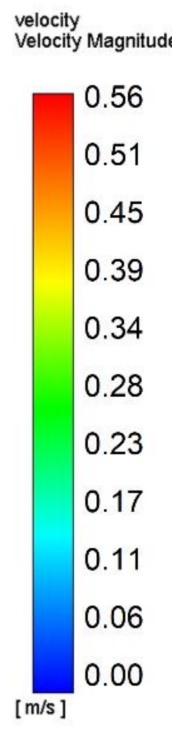

TSC

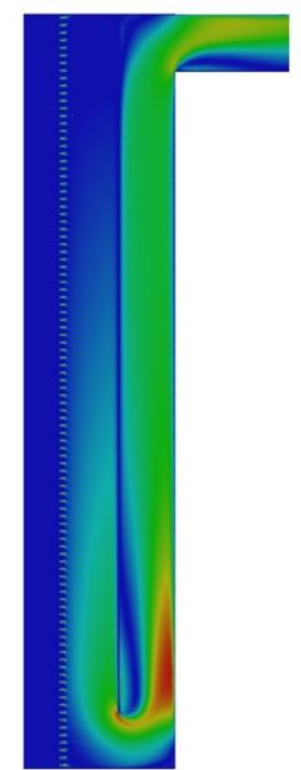

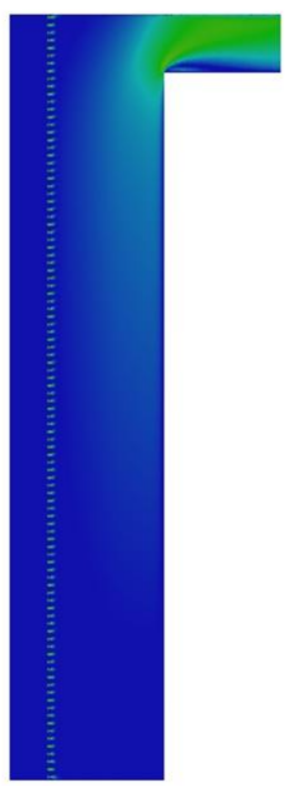

Figure 9. Velocity distribution in a median plane for the DSTSC (left) and TSC (right) at an air flow of $100 \mathrm{~m}^{3} / \mathrm{h}$.

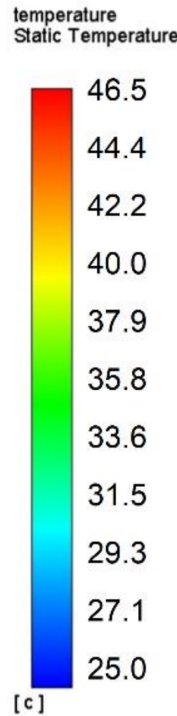

DSTSC

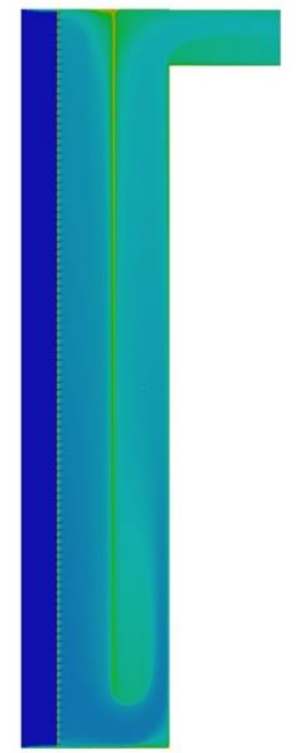

TSC

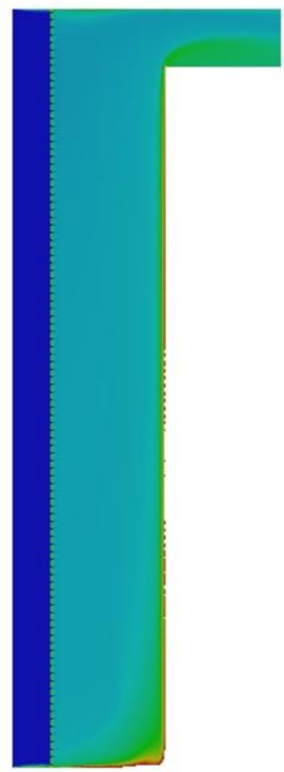

Figure 10. Temperature distribution in a median plane for the DSTSC (left) and TSC (right) at an air flow of $500 \mathrm{~m}^{3} / \mathrm{h}$.

The heat transfer coefficient was analyzed to characterize the thermal performance of the perforated absorber plate of each solar collector. Figure 12 shows the evolution of the heat transfer coefficient, and it is notable that the DSTSC has slightly better performance. However, if we consider the additional heat flux of the separation plate, the results are significantly different, as shown in Figure 13. Indeed, the thermal performance of the DSTSC now became much higher than the TSC. One limitation of these results, however, is that they do not include the heat flux of the back plate of both solar collectors. 
DSTSC

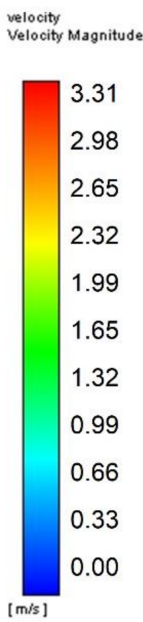

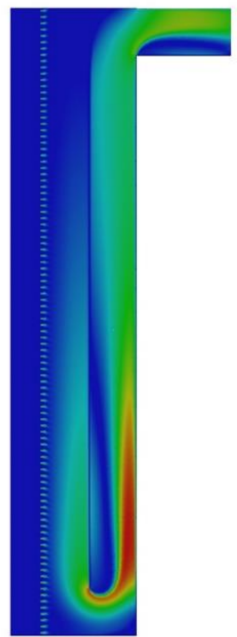

TSC

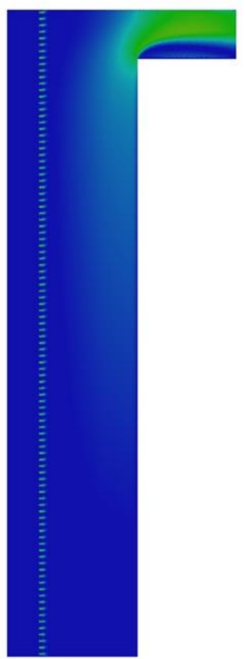

Figure 11. Velocity distribution in a median plane for the DSTSC (left) and TSC (right) at air flow of $500 \mathrm{~m}^{3} / \mathrm{h}$.

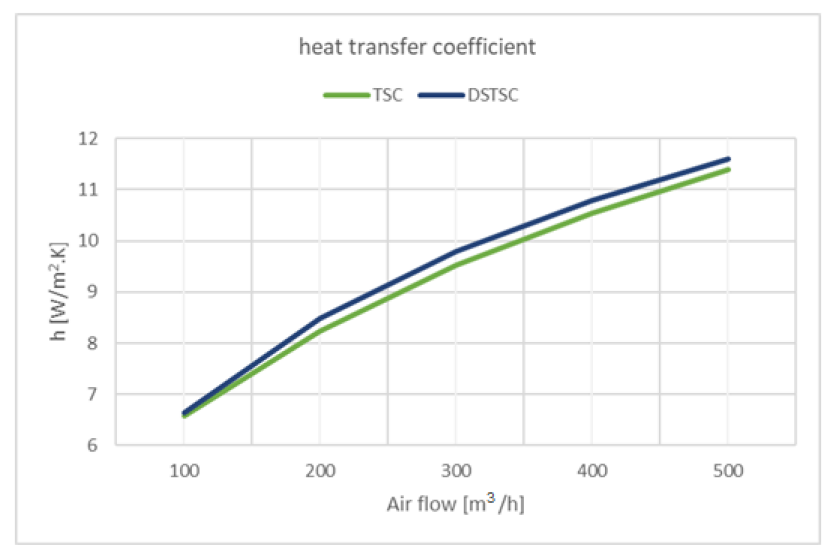

Figure 12. Computed results on the evolution of the heat transfer coefficient for the TSC and DSTSC.

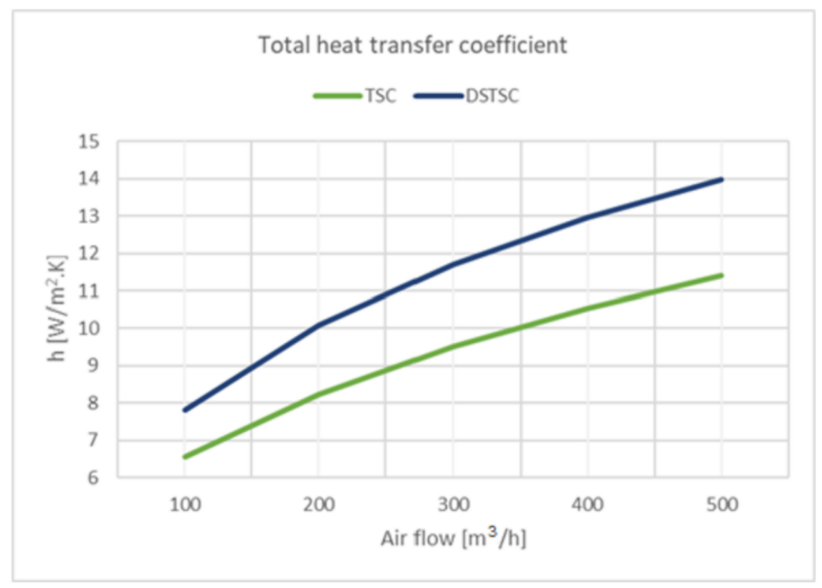

Figure 13. Computed results on the evolution of the total heat transfer coefficient for the TSC and DSTSC. 


\subsection{Investigation of the Air Layer Thickness Influence}

The aim of this part is to analyze the influence of the thickness of the DSTSC to determine the optimal thickness for the analyzed cases. The main objective is to make the DSTSC as thin as possible to be easier to install on the façades of buildings, to increase their acceptability towards the beneficiary, and to reduce the footprint of the building integrating such systems. From a realistic point of view, we limited our studies to a $30 \mathrm{~cm}$ solar air collector, considering the integration of such system in a building façade.

First, we investigated the temperature distribution on the perforated absorber plate. We can observe in Figure 14 that the thinnest DSTSC with a thickness of $10 \mathrm{~cm}$ overheats in the upper part of the absorber plate. This fact points out a reduction in the heat extracted from the absorber plate, and therefore, a drop in the efficiency of the collector. Additionally, we can notice a homogeneous temperature distribution in the perforated absorber plate of the $30 \mathrm{~cm}$ DSTSC.
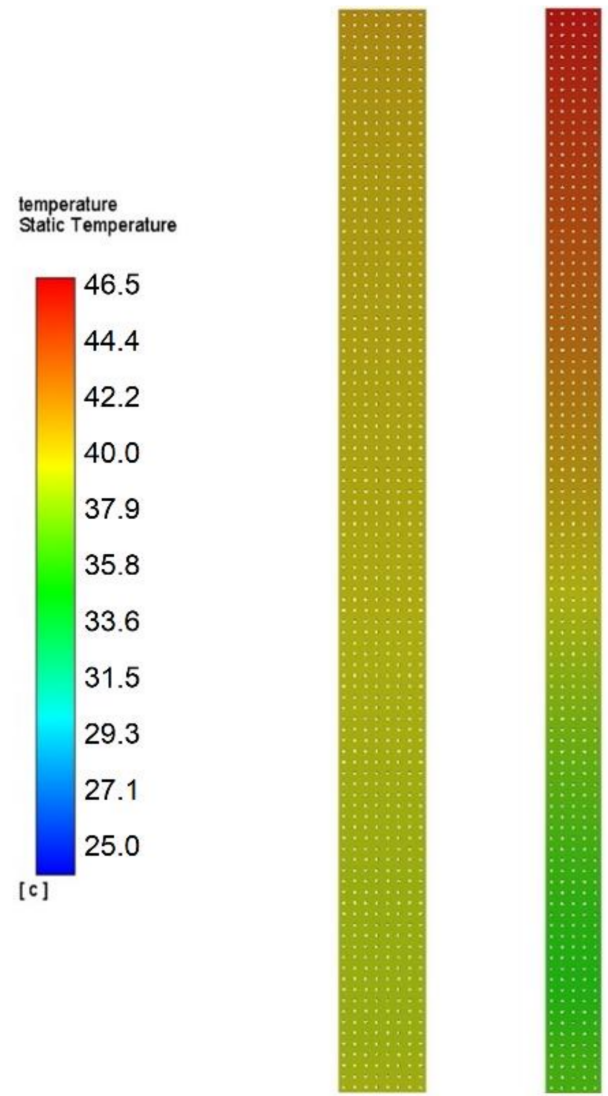

Figure 14. Distribution of the temperature on the perforated absorber plate of the $30 \mathrm{~cm}(\mathbf{l e f t})$ and $10 \mathrm{~cm}$ (right) thickness DTSC with an air flow of $500 \mathrm{~m}^{3} / \mathrm{h}$.

These facts led us to investigate the airflow distribution in both solar air collectors in more detail to determine the causes of the overheating of the absorber plate. Figure 15 presents the distribution of the air velocity magnitude in a median plane for both collectors and reveals the main cause leading to overheating. Indeed, part of the air sucked by the collector by-passed the holes in the upper part of the perforated absorber plate, leading to reduced airflow, and thus, reduced heat transfer. On the upper-left part of the Figure, a close-up view of the five upper holes of the absorber is presented, and this allows us to better appreciate and compare the velocity magnitudes for the two models of DSTSC.

Finally, we extracted data from numerical simulations to analyze the solar collector efficiency for the three analyzed cases, and the results are presented in Figure 16. The efficiency gradually increases when increasing the solar collector thickness, and we can 
observe that the $20 \mathrm{~cm}$ and $30 \mathrm{~cm}$ DSTSC reached close values. When varying the thickness from $30 \mathrm{~cm}$ to $10 \mathrm{~cm}$, we can notice a variation of about $4 \%$ regarding the solar collector efficiency for an air flow of $500 \mathrm{~m}^{3} / \mathrm{h}$.

3.00
2.70
2.40
2.10
1.80
1.50
1.20
0.90
0.60
0.30
0.00
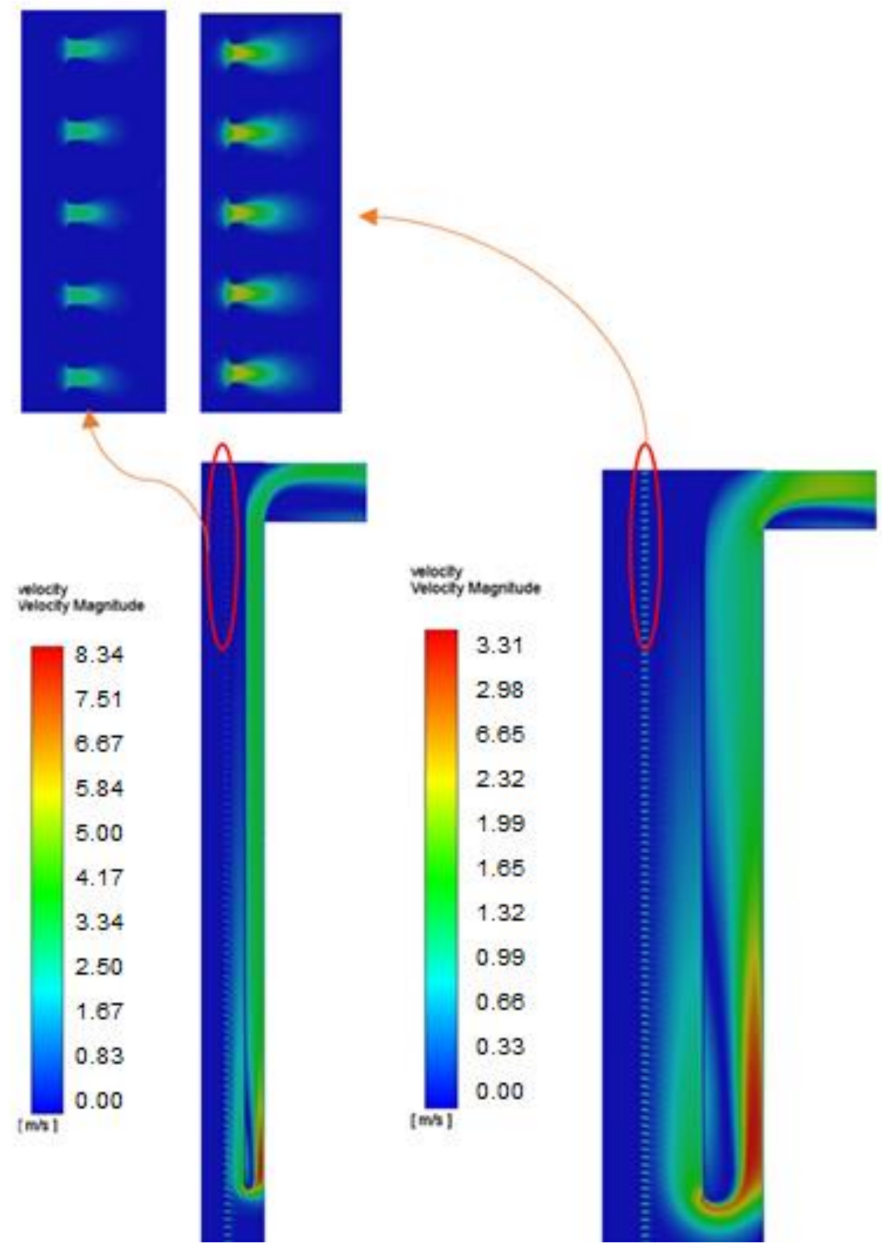

Figure 15. Distribution of the velocity magnitude in a median plane of both DSTSC, $10 \mathrm{~cm}$ (left) and $30 \mathrm{~cm}$ (right), for an air flow of $500 \mathrm{~m}^{3} / \mathrm{h}$.

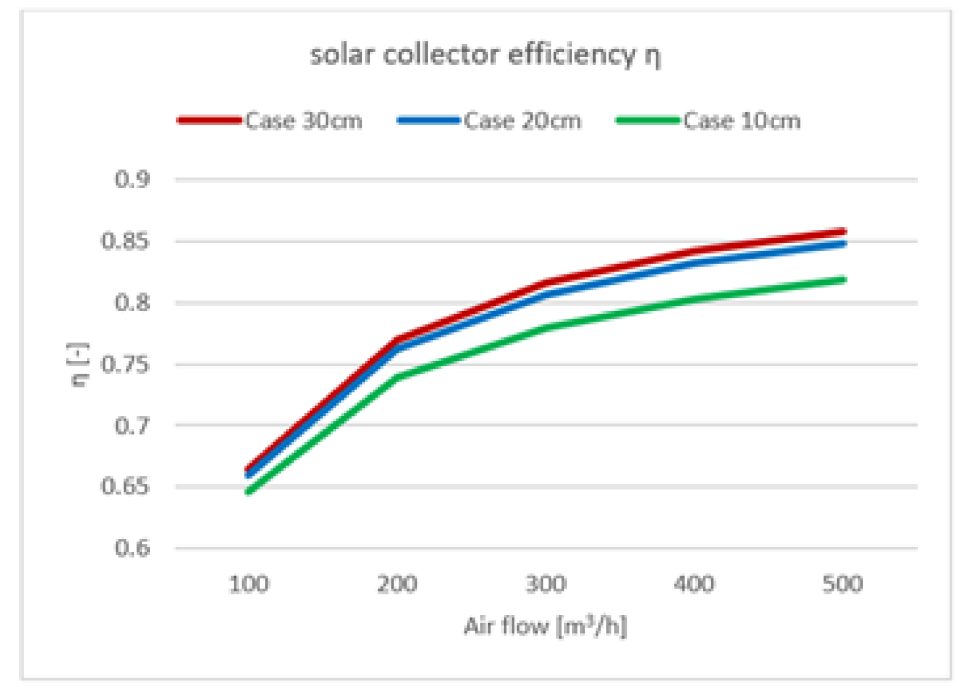

Figure 16. Solar collector efficiency for the three investigated collectors. 


\subsection{Influence of the Absorber Materials}

The aim of this part is to analyze the influence of the separation plate material. Our first thought was that a separation plate made of aluminum will increase the thermal performance of the solar collector. Indeed, an aluminum separation plate will collect the solar radiation passing through the perforated absorber plate and then release this energy to the air flowing through the collector.

However, an absorber plate made of a material such as aluminum is more expensive and has a higher environmental impact than an absorber plate made of based-wood, plastic, or recycled material. Thus, the aim of this chapter is to determine the energy gain provided by an aluminum absorber plate compared to other materials.

In addition, by using plastic in place of aluminum, we reduce the weight of the solar collector and then facilitate the use and implantation of such a system.

For this study, we analyzed the data collected from CFD simulations. Two materials were analyzed, namely, aluminium and high-density polyethylene with the specifications presented in Table 4.

Table 4. Materials' specifications.

\begin{tabular}{ccc}
\hline & HDPE & Aluminium \\
\hline Density $\left[\mathrm{kg} / \mathrm{m}^{3}\right]$ & 940 & 8030 \\
Thermal capacity $[\mathrm{J} / \mathrm{kg} \cdot \mathrm{K}]$ & 1900 & 502.48 \\
Thermal conductivity $[\mathrm{W} / \mathrm{m} \cdot \mathrm{K}]$ & 0.44 & 16.27 \\
Absorptivity & 0.8 & 0.8 \\
\hline
\end{tabular}

Three parameters were analyzed-the heat transfer coefficient, the heat exchanger efficiency, and the solar collector efficiency results are presented in Figures 17-19, respectively. The results found clear support for the slight impact of low-conductivity materials in TSC, as shown by Gawlik and Kutscher [11]. They are only slight differences between low and high thermal conductivity materials regarding the thermal performance of TSC. This is an important fact when you consider the cost of metal materials compared to plastic or plant fiber materials.

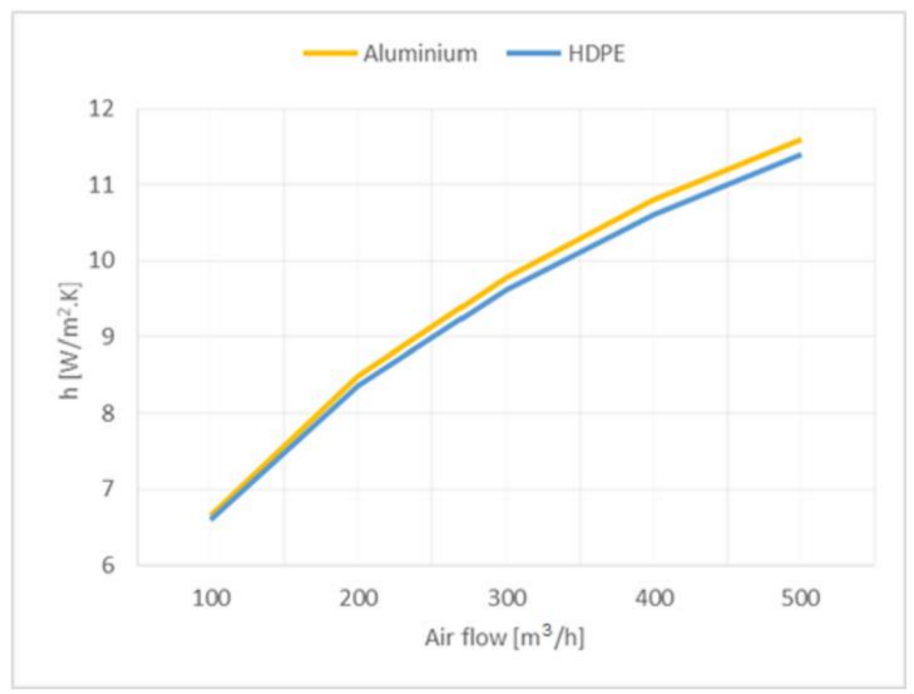

Figure 17. Computed results on the evolution of the heat transfer coefficient for Aluminum and HDPE absorber. 


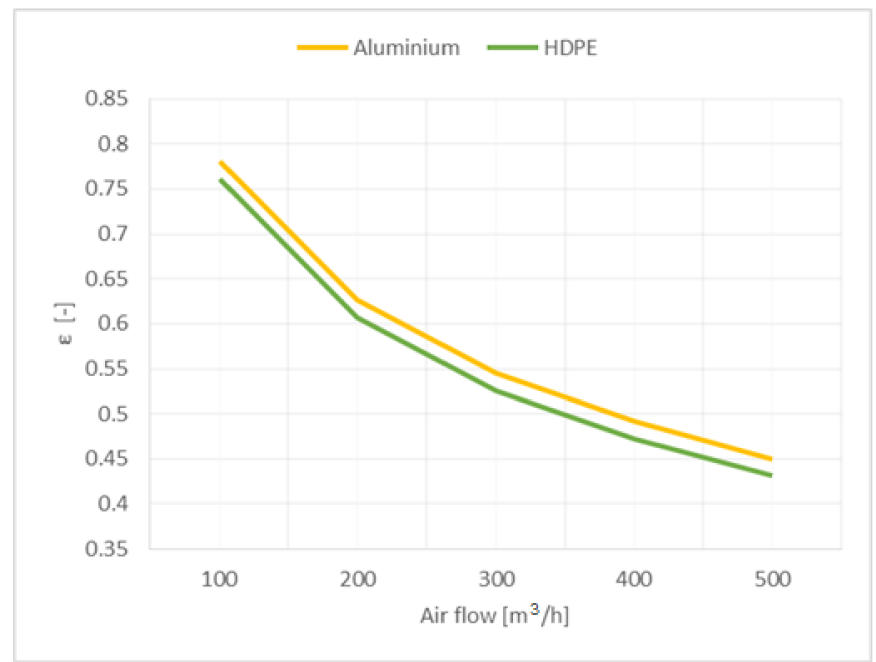

Figure 18. Evolution of the heat exchanger efficiency for Aluminum and HDPE absorber.

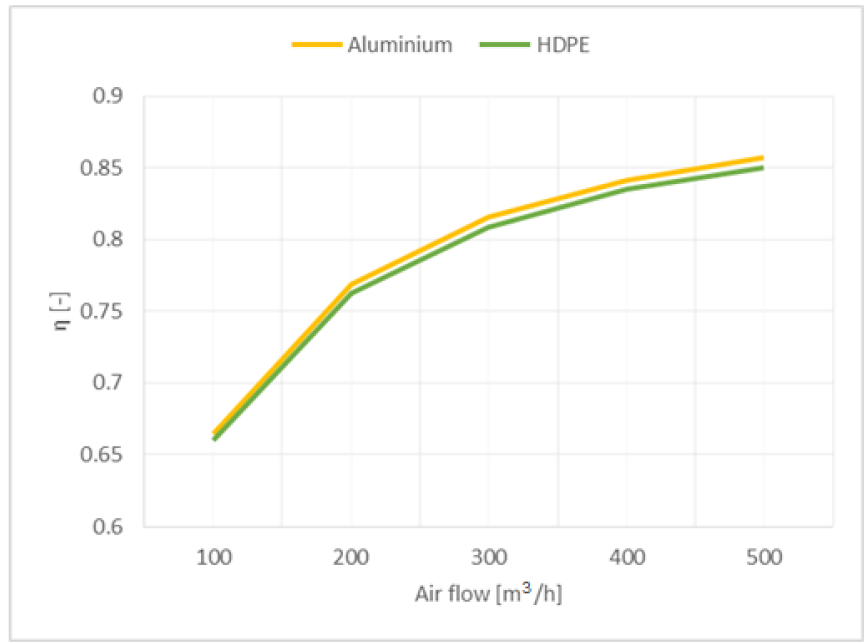

Figure 19. Evolution of the solar collector efficiency for Aluminum and HDPE absorber.

Figure 20 shows the non-uniformity of the temperature distribution caused by lowconductivity materials. We can notice that the HDPE perforated absorber plate slightly overheated in the extreme upper and bottom part. However, non-uniform thermal behavior does not have a major impact on the solar collector efficiency, as reported before. 


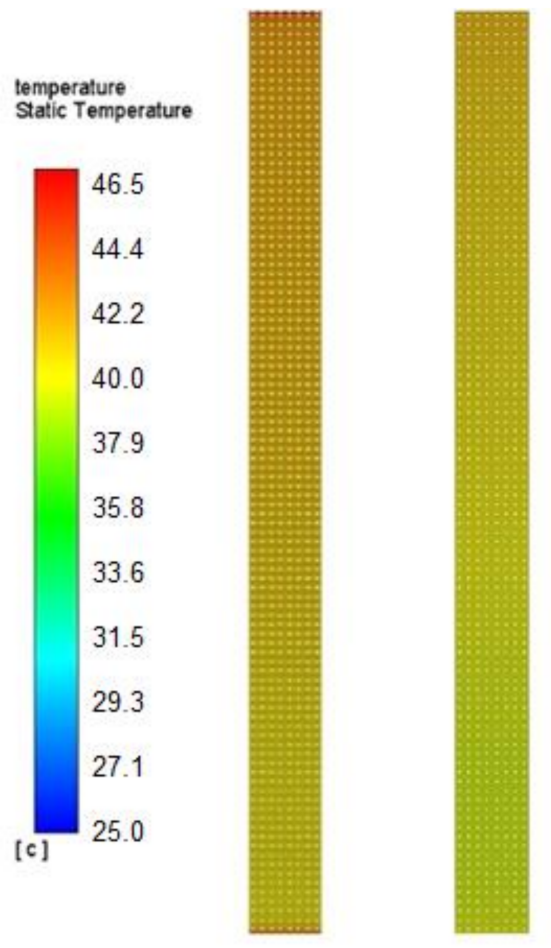

Figure 20. Distribution of the temperature on the perforated absorber plate of the HDPE (left) and Aluminum (right) with an air flow of $500 \mathrm{~m}^{3} / \mathrm{h}$.

\section{Conclusions}

A novel double skin transpired solar collector was analyzed via CFD simulations aiming to determine the thermal behaviour and performance of such a system, thus providing guiding values and a technical point of view for engineers, architects, and constructors when designing such transpired solar collectors.

The numerical grid used for the numerical simulation was verified in a previous article on this issue in terms of a mesh independency test. Additionally, validation of the numerical results with experimental measurements was performed to trust the conclusions of the numerical results.

Three important parameters less studied in the literature were addressed in this study, namely: the influence of a separation plate introduced in a transpired solar collector turning it into a double skin transpired solar collector, the influence of air layer thickness on the performance of the collector, and the influence of the used absorber materials for the separation plate material.

The numerical simulation studies have shown that a separation plate placed inside the solar air collector will not negatively impact the thermal performance of the solar air collector, but quite the opposite-results demonstrate that the DSTSC has slightly better thermal performances than TSC in the studied range of airflow. Additionally, higher heat exchanger efficiency for the DSTSC at every imposed airflow rate can be noticed compared with the TSC. All this shows the potential of the DSTSC prototype for future use integrating latent heat thermal storage in the back-pass.

The influence of the DSTSC thickness was also investigated. Results have shown that if the DSTSC is too thin, it is susceptible to overheating in the upper part of the absorber plate. The efficiency gradually increases when increasing the solar collector thickness until it reaches a value of $20 \mathrm{~cm}$. For a thickness of $30 \mathrm{~cm}$, DSTSC reached close values with a $20 \mathrm{~cm}$ case. When varying the thickness from $30 \mathrm{~cm}$ to $10 \mathrm{~cm}$ we were able to notice a variation of about $4 \%$ regarding the solar collector efficiency for an airflow of $500 \mathrm{~m}^{3} / \mathrm{h}$. 
The numerical study was performed for steady-state conditions, not considering the wind influence, as the time-step is too small for the current computational capabilities. Additionally, the simulation period was limited to a typical summer day, but further investigation should be performed to overcome these limitations.

Regarding the influence of the used absorber materials for the separation plate material, the results indicate that low-conductivity material does not have homogeneous thermal behaviour when comparing to high-conductivity material; however, for Transpired Solar Air Collectors, the differences regarding thermal performances are not significant. Thus, low-conductivity materials are conceivable for TSCs, especially since their price remains lower. These results cast new light on alternative materials for solar air collectors, especially since recycled materials have particular interest in buildings construction. The balance between quality and price is interesting for low-conductivity materials, and this allows this type of collector to be low-cost and low-tech, which is very interesting for new low-carbon policies and for the development of these technologies in developing countries looking for reliable and cheap products.

However, this led us to ask ourselves several open questions about the durability of such materials for this type of technology. First, plastic-based materials can be harmful to air quality and health [22,23]. Indeed, they can release fine plastic particles or even release harmful particles when they heat up. Interesting research questions for future research that can be derived from this topic regard the feasibility of low-conductivity materials, such as plastic, with a holistic approach, integrating energy efficiency, air quality, and health.

Author Contributions: Conceptualization, C.B. and C.C.; methodology, C.B.; software, F.B.; validation, F.B., C.B.; formal analysis, C.B.; investigation, C.B.; resources, C.C.; data curation, C.B.; writing-original draft preparation, C.B.; writing-review and editing, C.C. and F.B.; visualization, F.B.; supervision, C.C.; project administration, C.C. and C.B.; funding acquisition, C.C. All authors have read and agreed to the published version of the manuscript.

Funding: This research was funded by Romanian National Authority for Scientific Research-UEFISCDI grant number PN-III-P2-2.1-PED-2019-4165.

Institutional Review Board Statement: Not applicable.

Informed Consent Statement: Not applicable.

Acknowledgments: The authors gratefully acknowledge the financial support of the Romanian National Authority for Scientific Research, project BISCUIT “Building integrated solar crop dryer for food preservation in urban farming applications" PN-III-P2-2.1-PED-2019-4165.

Conflicts of Interest: The authors declare no conflict of interest.

\section{References}

1. Ahmad, T.; Zhang, D. A critical review of comparative global historical energy consumption and future demand: The story told so far. Energy Rep. 2020, 6, 1973-1991. [CrossRef]

2. Commission, E.; (Communication from the Commission to the European Parliament, the Council, the European Economic and Social Committee and the Committee of the Regions a Renovation Wave for Europe-Greening Our Buildings, Creating Jobs, Improving Lives, Brussels, Belgium). Personal communication, 2020.

3. Talaei, M.; Mahdavinejad, M.; Zarkesh, A.; Motevali Haghighi, H. A Review on Interaction of Innovative Building Envelope Technologies and Solar Energy Gain. Energy Procedia 2017, 141, 24-28. [CrossRef]

4. Luo, Y.; Zhang, L.; Bozlar, M.; Liu, Z.; Guo, H.; Meggers, F. Active building envelope systems toward renewable and sustainable energy. Renew. Sustain. Energy Rev. 2019, 104, 470-491. [CrossRef]

5. Peci, F.; Taboas, F.; Comino, F.; Ruiz de Adana, M. Experimental study of a modular Unglazed transpired collector Façade for building refurbishment. Sol. Energy 2020, 201, 247-258. [CrossRef]

6. Bokor, B.; Akhan, H.; Eryener, D.; Horváth, M. Nocturnal passive cooling by transpired solar collectors. Appl. Therm. Eng. 2021, 188, 116650. [CrossRef]

7. Gunnewiek, L.H.; Brundrett, E.; Hollands, K.G.T. Flow distribution in unglazed transpired plate solar air heaters of large area. Sol. Energy 1996, 58, 227-237. [CrossRef]

8. Gunnewiek, L.H.; Hollands, K.G.T.; Brundrett, E. Effect of wind on flow distribution in unglazed transpired-plate collectors. Sol. Energy 2002, 72, 317-325. [CrossRef] 
9. Van Decker, G.W.E.; Hollands, K.G.T.; Brunger, A.P. Heat-exchange relations for unglazed transpired solar collectors with circular holes on a square or triangular pitch. Sol. Energy 2001, 71, 33-45. [CrossRef]

10. Gawlik, K.M.; Kutscher, C.F. Wind heat loss from corrugated, transpired solar collectors. J. Sol. Energy Eng. 2002, 124, 256-261. [CrossRef]

11. Gawlik, K.M.; Kutscher, C.F. A numerical and experimental investigation of low-conductivity unglazed, transpired solar air heaters. In Proceedings of the International Solar Energy Conference, Reno, NV, USA, 15-20 June 2002; pp. 47-55.

12. Tajdaran, S.; Kendrick, C.; Hopkins, E.; Bonatesta, F. Geometrical optimisation of Transpired Solar Collectors using design of experiments and computational fluid dynamics. Sol. Energy 2020, 197, 527-537. [CrossRef]

13. Bake, M.; Shukla, A.; Liu, S.; Agrawal, A. A systematic review on parametric dependencies of transpired solar collector performance. Int. J. Energy Res. 2019, 43, 86-112. [CrossRef]

14. Croitoru, C.V.; Nastase, I.; Bode, F.I.; Meslem, A. Thermodynamic investigation on an innovative unglazed transpired solar collector. Sol. Energy 2016, 131, 21-29. [CrossRef]

15. Bejan, A.S.; Teodosiu, C.; Croitoru, C.V.; Catalina, T.; Nastase, I. Experimental investigation of transpired solar collectors with/without phase change materials. Sol. Energy 2021, 214, 478-490. [CrossRef]

16. Wang, D.; Gao, M.; Gao, Q.; Liu, Y.; Liu, Y.; Liu, J. Experimental and numerical study of the airflow and thermal characteristic of non-uniform transpired solar collector. Build. Simul. 2020, 13, 1305-1319. [CrossRef]

17. Wang, X.; Lei, B.; Bi, H.; Yu, T. A simplified method for evaluating thermal performance of unglazed transpired solar collectors under steady state. Appl. Therm. Eng. 2017, 117, 185-192. [CrossRef]

18. Berville, C.; Tetang Fokone, A.; Sima, C.I.; Croitoru, C.V. Mesh independency study for an unglazed transpired solar collector. IOP Conf. Ser. Earth Environ. Sci. 2021, 664, 012059. [CrossRef]

19. Wang, Y.; Shukla, A.; Liu, S. A state of art review on methodologies for heat transfer and energy flow characteristics of the active building envelopes. Renew. Sustain. Energy Rev. 2017, 78, 1102-1116. [CrossRef]

20. Li, S.; Karava, P.; Savory, E.; Lin, W.E. Airflow and thermal analysis of flat and corrugated unglazed transpired solar collectors. Sol. Energy 2013, 91, 297-315. [CrossRef]

21. Sima, C.; Teodosiu, C.; Berville, C. Mesh Independency Study for a Solar Glazed Transpired Collector. In Proceedings of the International Conference Building Services And Energy Efficiency Iasi 2020; Sciendo, Poland, 2020; pp. 60-68.

22. van Drooge, B.L.; Rivas, I.; Querol, X.; Sunyer, J.; Grimalt, J.O. Organic Air Quality Markers of Indoor and Outdoor PM2.5 Aerosols in Primary Schools from Barcelona. Int. J. Environ. Res. Public Health 2020, 17, 3685. [CrossRef]

23. Porada, E.; Szyszkowicz, M. UNMIX Methods Applied to Characterize Sources of Volatile Organic Compounds in Toronto, Ontario. Toxics 2016, 4, 11. [CrossRef] 